\title{
A systematic review of in-patients' antimicrobial prescriptions and status of antimicrobial stewardship programmes in Nigerian hospitals
}

\author{
Chinonyerem O. Iheanacho ${ }^{1^{*}}$ (ID and Uchenna I. H. Eze ${ }^{2}$
}

\begin{abstract}
Background: Antimicrobial resistance is a major consequence of irrational antimicrobial prescriptions and consumptions, but this can be prevented by antimicrobial stewardship. The study systematically reviewed available evidence on antimicrobial prescriptions and antimicrobial stewardship (AMS) programmes in Nigerian hospitals. This will provide insight to the extent of required interventions, for improved healthcare.

Main body: Published research from January 12010 to March 312021 from PubMed, Scopus, Web of Science, African Journals Online and Google scholar databases was reviewed using Preferred Regulatory Items for Systematic Reviews and Meta-Analysis (PRISMA) guidelines 2009. Studies that reported antimicrobial use and antimicrobial stewardship programmes in Nigerian hospitals within the period in focus were assessed for eligibility. The National Heart, Lung and Blood Institute (NHLBI) quality assessment tool was used to assess quality of included studies. Among 15 studies included based on inclusion criteria, 12 reported on antimicrobial prescriptions and 3 reported on status of antimicrobial stewardship programmes in Nigerian hospitals. Most studies reported high prevalence of antimicrobials prescriptions with broad spectrum antimicrobials, majority of which were inappropriate. Empirical antimicrobial prescribing was common, and this was mostly done with less cognisance to existing guidelines. Only few hospitals were observed to have formal AMS teams in Nigeria.
\end{abstract}

Conclusion: Inappropriate prescribing of antimicrobials was common among prescribers in Nigeria. Although there was paucity of studies on status of AMS, the available few showed very low prevalence of AMS teams in hospitals. There is urgent need for implementation of AMS in Nigerian hospitals, to enhance rational antimicrobial use. Meanwhile more research on AMS in Nigerian hospitals is needed.

Keywords: Antimicrobial prescriptions, Antimicrobial stewardship programmes, Nigerian hospitals, Antibiotics, In-patients

*Correspondence: nonye2m@yahoo.com

1 Department of Clinical Pharmacy and Public Health, Faculty of Pharmacy, University of Calabar, PMB 1115, Calabar, Cross River State, Nigeria

Full list of author information is available at the end of the article

\begin{abstract}
Background
Antimicrobials are essential in preventing and treating microbial infections originating from community or hospital settings [1]. It is a general term used to represent a group of drugs that includes antibiotics, antifungals, antiviral and antiprotozoal [2]. Antimicrobial prescription is an important process of selecting and ordering for antimicrobials to proffer therapy or
\end{abstract}


prevent microbial infections. It involves formulation of appropriate antimicrobial regimen from several options and requires rational prescription skills. Rational prescription of antibiotics is a process that emphasises the provision of appropriate antimicrobial that adequately meets the clinical needs of a patient in individualised doses for an appropriate duration and at the lowest cost [3]. Prescription process may encounter selection of sub-optimal or inappropriate antibiotics [4], therefore several guidelines have been developed to prevent this occurrence. Antimicrobial stewardship (AMS) teams and programmes are also instituted to provide checks, and limit the occurrence of irrational antimicrobial prescriptions.

Antimicrobial stewardship is a coherent and coordinated set of actions that ensure responsible use of antimicrobials [5]. This is achieved through various AMS programmes which involve implementation of evidencebased interventions in a system through several care strategies. Audit of antimicrobial prescriptions is an essential strategy to identify areas of stewardship interventions. AMS is a World Health Organisation strategy for antimicrobial resistance (AMR) control, and encourages rational antimicrobial prescribing in terms of dose, appropriateness and duration [6]. Although AMS aims to optimise the use of antimicrobial medicines, concerted leadership commitment is an essential catalyst towards establishing AMS programmes in hospitals. This requires dedicated human, financial and information technology system, and accountable leaders for the team [7].

Although good knowledge of appropriate antimicrobial prescriptions exists among prescribers in Nigeria, there is low translation of this knowledge in practice [8]. Persistent and overuse of empiric antimicrobial regimen among physicians in Nigeria's health care settings [9-12], and redundant prescriptions [13], with extensive use of broad spectrum antimicrobials [12] portray an urgent need for efficient AMS in the country. Inappropriate prophylactic and therapeutic use of antibiotics [14], and commonly reported high prevalence (62.4-94.6\%) of antimicrobials among in-patients in Nigeria [15-17], pose a major source of concern. Considering the established relationship between antimicrobial consumption and AMR [18], evaluation of appropriateness and completeness of antimicrobial prescriptions and monitoring of its consumption are important means of preventing AMR [19]. Therefore with adequate support from all stake holders, AMS should be an essential component of patient care for effective control of AMR. Meanwhile, there is limited data that describes the availability and status of formal AMS teams in Nigerian hospitals. Inadequate implementation of AMS strategies is also recognised in the country [20], although AMS is a component of the Nigerian national AMR action plan 2017-2022 [21].

This study systematically reviewed available evidence on antimicrobial prescriptions for hospitalised patients, and status of antimicrobial stewardship programmes in Nigerian hospitals. This is expected to provide insight to the extent of required interventions for improved infection control and health outcomes.

\section{Main body \\ Study design}

The review was performed in accordance with Preferred Reporting Items for Systematic Reviews and Meta-Analysis (PRISMA) guidelines 2009 [22]. Systematic review of peer-reviewed eligible articles was conducted from electronic databases of PubMed, Scopus, African Journals Online (AJOL), Web of Science and Google scholar from January 1, 2010 to March 31, 2021.

\section{Search strategy}

Authors conducted the search independently to reduce bias, and keywords were used in different combinations for the search. The keywords were; Antimicrobial use, Antimicrobial prescriptions, Antibiotics prescriptions, Hospitals, Healthcare facilities, Nigeria, Stewardship, Antifungal use, Antibacterial prescriptions, Antiviral use, Antiprotozoal use.

\section{Study eligibility}

After a careful assessment of titles and screening of abstracts of potential studies, only articles that reported studies on antimicrobial prescribing in Nigerian hospitals and the state of antimicrobial stewardship programmes in Nigerian hospital were assessed for eligibility.

\section{Inclusion and exclusion criteria}

Duplicates where eliminated and full text of papers were independently reviewed by the authors to determine the quality of the articles. A random $10 \%$ of titles was also checked by an author to ensure relevant titles were not excluded.

\section{Inclusion criteria}

1. Original articles that reported prescriptions and use of antimicrobials in Nigerian hospitals.

2. Original articles that evaluated the state of antimicrobial stewardship programmes in Nigerian hospitals.

3. All included studies were written in English language and reported the outcomes of interest. 


\section{Exclusion criteria}

1. Articles were excluded if they were:

2. Reviews, correspondences, viewpoints and commentaries

3. Not conducted in Nigeria

4. Studies conducted in community settings

5. Studies conducted on out-patients' antimicrobial prescribing

6. Studies on healthcare professionals knowledge, perceptions and attitudes to antimicrobial prescribing and AMS.

\section{Outcome measures}

Primary outcome of interest was prescriptions of antimicrobials for hospitalised patients, and the secondary outcome measure was presence of formal antimicrobial stewardship programme teams.

\section{Evaluation of the selected studies and method of risk of bias assessment}

Critical evaluation of all included studies was done, and outcomes of interests were noted. Individual studies were assessed for limitations at the study level. Quality of included studies was assessed using the National Heart, Lung and Blood Institute (NHLBI) quality assessment tool.

\section{Data extraction and synthesis}

Extraction of data from reports was independently done to reduce the risk of bias. Data extracted from each study included study authors, study period, number of hospitals involved, type of in-patients, study design, study size and results. Results were categorised into 4 sections.

\section{Search results}

A total of 1851 titles were retrieved from search of the databases, from which 143 abstracts were further assessed, and 15 studies met the inclusion criteria of our review. Summary of studies selection is shown in the PRISMA flow diagram (Fig. 1).

\section{Characteristics of included studies}

A total of 12 studies discussed antimicrobial prescriptions among hospital in-patients, including pattern of prescriptions and antimicrobials most frequently prescribed. None of the studies was conducted between 2010 and 2013, while one study each, was conducted in 2014, 2015, 2018 and 2021 respectively. Three of the studies

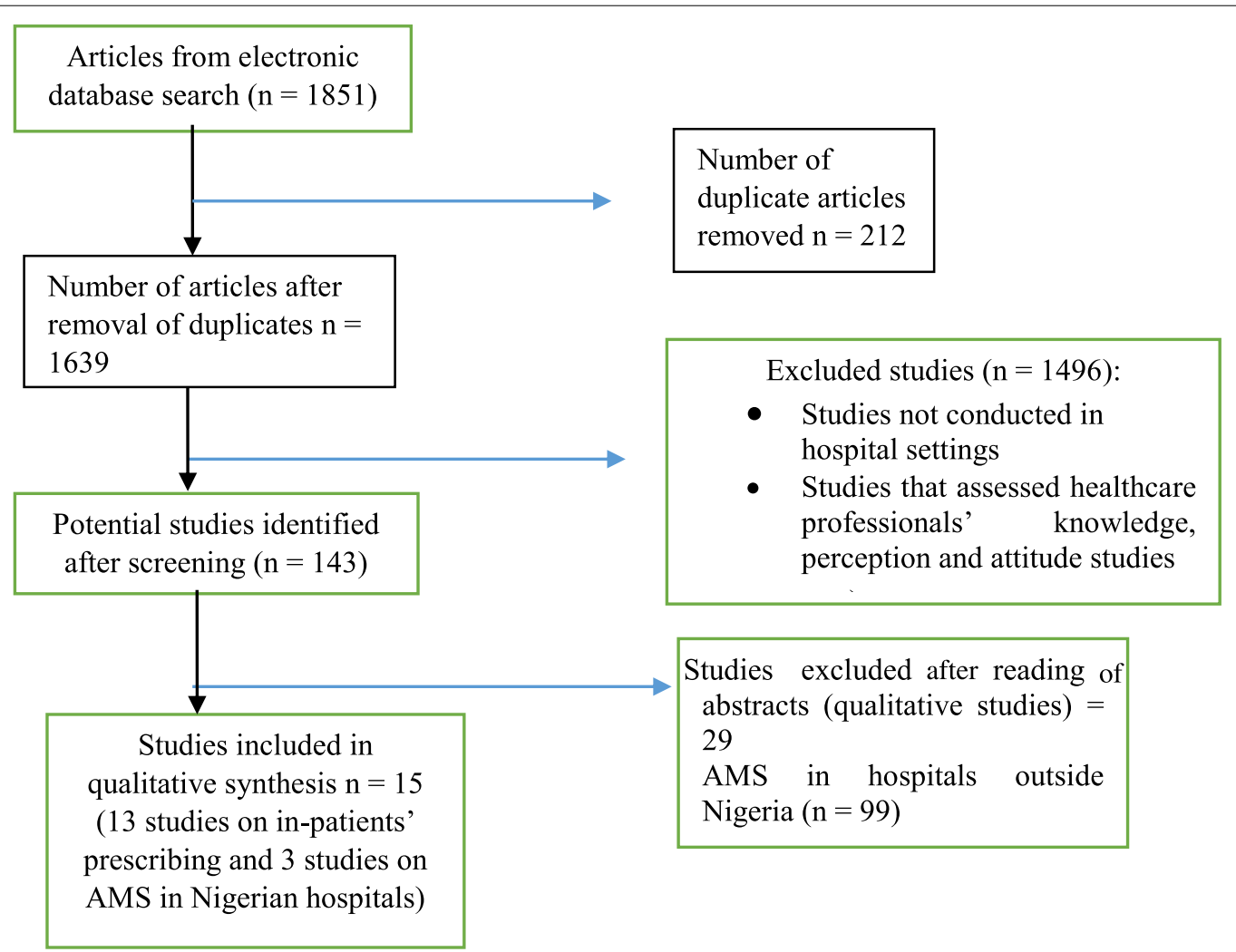

Fig. 1 PRISMA flow diagram of study selection 
were conducted in 2016 and 2019 respectively, while 2 studies were in 2017. All the included studies were peerreviewed. Cross-sectional study design was utilised in 6 studies, while 5 studies employed the retrospective study design and 1 study employed mixed method (cross-sectional and retrospective). See Table 1. From the NHLBI quality assessment, high quality was found in the majority of studies. Three studies reported findings on status of formal antimicrobial stewardship teams in hospitals (Table 2), and the 3 studies utilised cross-sectional study design.

\section{Antimicrobial prescriptions in Nigerian hospitals}

A study by Umeokonkwo et al. noted that antimicrobials were mostly prescribed empirically [15], suggesting the need for education of prescribers on antimicrobial stewardship. Limited use of guidelines was also observed by the researchers in their study which comprised 220 in-patients. Highest prevalence of antimicrobial prescriptions was found in ICU, surgical ward and paediatrics medical ward respectively. Most frequently used antimicrobials as noted in the study were broad spectrum, and included third generation cephalosporin (ceftriazone) and nitroimidazole (metronidazole). The study had clearly defined objectives, and illustrates a state of high antimicrobial prescriptions and less regards to guidelines. This is highly suggestive of relevant intervention strategies, including AMS.

Similar findings were reported by Abubakar [17], and highest prevalence of antibiotic use was observed in the paediatrics specialty. The researcher also noted that broad spectrum antibiotics were mostly prescribed, and prescriptions were for community acquired infections and surgical prophylaxis. Meanwhile, redundant prescriptions and unduly prolonged prophylaxis were observed in the study. This suggests a dire need for formal and effective AMS teams in hospitals to promote appropriate antimicrobial prescribing. Although, review of patients' charts for antimicrobial prescriptions provided objective findings about prescriptions, it may not be representative of the regular practice as a result of its study design. Similarly, the inclusion of only 3 hospitals in the same region may limit generalisation of findings. As noted by the researcher, the appropriateness of antibiotic prescription among the patients was not evaluated in the study. Small sample size is another major limitation of the study.

Consistent with aforementioned reports, Fowotade and colleagues observed high prescriptions of broad spectrum antimicrobials in their study [23]. Third generation cephalosporine (ceftriazone), penicillins and floroquinolone respectively, were most frequently used and over half of the study patients received at least one antimicrobial on the day of survey. Meanwhile, only few of the antibiotics had documented "stop or review date", which may be a potential lead to unnecessarily prolonged therapy or sub-optimal duration of therapy. Reasons for antibiotics prescriptions were documented in the majority of cases, but targeted therapy was observed in only few cases, non-adherence to existing guidelines was also noted in the study by the researchers. Other pointers to non-rational antimicrobial prescriptions as reported in the study were prolonged surgical prophylaxis, low utilisation of laboratory facilities and non-existence of institutional guidelines for antimicrobial prescriptions. Development of institutional antibiotic guidelines and antimicrobial stewardship programmes are relevant interventions for rational antimicrobial prescriptions.

Similarly, in a mixed method study by Kpokiri et al. [24] antibiotic use was reported mostly in person $\leq 16$ years of age. High rate of empirical prescribing was observed in the study, and broad spectrum antimicrobials were commonly prescribed, among which were ciprofloxacin, amoxicillin and clavulanic acid, metronidazole and cefuroxime. The study also noted low utilisation of microbiology laboratory tests, which is relevant to providing objective diagnosis for microbial infections. Particularly, culture and sensitivity tests were rarely employed for guidance on antimicrobial treatment decisions, as reported by Kpokiri et al. [25] Physicians' confidence in efficiency of clinical diagnosis, among other reasons as noted in previous report, may have been a leading cause of this practice. Meanwhile relevant laboratory tests did not show evidence of bacterial infection in some of the patients who were prescribed antibiotic medications. Poor adherence to Nigeria standard treatment guidelines was also noted among the prescribers. Potential self-reporting bias may be associated with the qualitative survey of the physicians.

In another retrospective study of the use of surgical antimicrobial prophylaxis (SAP), Oshikoya et al. [26] observed that only very few prescribers fully complied with international guidelines for SAP. SAP guidelines were mostly violated in terms of correct timing and duration of antimicrobial use. Broad spectrum antibiotics were most prescribed, and almost half were under-dosed. The study employed review of patients' charts for the retrieval of antimicrobial prescriptions, which potentially minimised the risk of bias. Meanwhile, it was a single centre study with potentials of unique hospital prevailing pattern of antimicrobial use, therefore findings may not be generalisable.

Poor utilisation of laboratory findings in making antimicrobial prescribing decisions was also noted by Ogunleye et al. [11]. Empirical prescribing was preferred, and other factors that influenced prescriptions were 
Table 1 Characteristics of studies on in-patients' antimicrobial prescriptions

\begin{tabular}{|c|c|c|c|c|}
\hline References & Study design & Major findings & Strengths & Limitations \\
\hline Umeokonkwo et al. [15] & Cross-sectional & $\begin{array}{l}\text { Less utilisation of available } \\
\text { antimicrobial guidelines } \\
\text { High prevalence of antimicro- } \\
\text { bial prescribing }\end{array}$ & $\begin{array}{l}\text { Sample size was determined } \\
\text { and justified }\end{array}$ & Single centre \\
\hline Abubakar, [17] & Cross-sectional & $\begin{array}{l}\text { High prevalence of antimicro- } \\
\text { bial use } \\
\text { Broad spectrum antimicrobials } \\
\text { were most frequently used } \\
\text { Prolonged surgical prophylaxis } \\
\text { was observed }\end{array}$ & $\begin{array}{l}\text { Study included both second- } \\
\text { ary and tertiary hospitals } \\
\text { Case files were reviewed for } \\
\text { actual antimicrobial prescrip- } \\
\text { tions } \\
\text { Justifiable sample size }\end{array}$ & $\begin{array}{l}\text { Antimicrobial exposure was } \\
\text { assessed once, and so may not } \\
\text { be representative of routine use } \\
\text { in the hospitals }\end{array}$ \\
\hline Fawotade et al. [23] & Cross-sectional & $\begin{array}{l}\text { Broad spectrum antimicrobi- } \\
\text { als were most commonly } \\
\text { prescribed } \\
\text { Non-existent compliance to } \\
\text { guidelines was observed }\end{array}$ & $\begin{array}{l}\text { Study included all the in- } \\
\text { patients in all the wards }\end{array}$ & $\begin{array}{l}\text { Antimicrobial prescriptions was } \\
\text { assessed once }\end{array}$ \\
\hline Kpokiri et al. [24] & $\begin{array}{l}\text { Retrospective and } \\
\text { cross-sectional (mixed } \\
\text { method) }\end{array}$ & $\begin{array}{l}\text { Broad spectrum antimicrobials } \\
\text { were most commonly used } \\
\text { Relevant microbiological tests } \\
\text { showed no evidence of need } \\
\text { for some of the prescriptions } \\
\text { Low observance of Nigeria } \\
\text { standard treatment guideline }\end{array}$ & $\begin{array}{l}\text { Included secondary and ter- } \\
\text { tiary healthcare facilities }\end{array}$ & Potential self-reporting bias \\
\hline Oshikoya et al. [26] & Retrospective & $\begin{array}{l}\text { Broad spectrum antimicrobi- } \\
\text { als were most commonly } \\
\text { prescribed } \\
\text { Poor compliance with interna- } \\
\text { tional SAP guidelines } \\
\text { Under-dosing of most antimi- } \\
\text { crobials }\end{array}$ & $\begin{array}{l}\text { Well defined study objectives } \\
\text { Uniform inclusion and } \\
\text { exclusion criteria for study } \\
\text { population }\end{array}$ & Single centre \\
\hline Ogunleye et al. [11] & Cross-sectional & $\begin{array}{l}\text { Antimicrobial prescriptions } \\
\text { was commonly based on clini- } \\
\text { cal judgment }\end{array}$ & Good sample size effect & $\begin{array}{l}\text { Potential self-reporting bias } \\
\text { Exposure was assessed once }\end{array}$ \\
\hline Abubakar et al. [14] & Cross-sectional & $\begin{array}{l}\text { Observed redundant antimi- } \\
\text { crobial prescriptions } \\
\text { Broad spectrum antimicrobials } \\
\text { was mostly used }\end{array}$ & $\begin{array}{l}\text { Clearly defined and valid } \\
\text { outcome measures }\end{array}$ & $\begin{array}{l}\text { Lack of randomisation } \\
\text { Incomplete surveillance for sur- } \\
\text { gical infections among patients } \\
\text { Primary and secondary hospitals } \\
\text { were excluded, limiting gener- } \\
\text { alisation }\end{array}$ \\
\hline Roberts et al. [10] & Retrospective & $\begin{array}{l}\text { Unnecessary antimicrobial use } \\
\text { in some patients } \\
\text { Poor practice of relevant labo- } \\
\text { ratory tests prior prescription } \\
\text { Few prescribers complied with } \\
\text { departmental guidelines }\end{array}$ & $\begin{array}{l}\text { Well defined objectives and } \\
\text { reliable outcome measures }\end{array}$ & $\begin{array}{l}\text { Single centre which limits } \\
\text { generalisation }\end{array}$ \\
\hline Efunshile et al. [9] & Cross-sectional & $\begin{array}{l}\text { High prevalence of antibiot- } \\
\text { ics use } \\
\text { Antibiotics were prescribed } \\
\text { without apparent medical } \\
\text { indications }\end{array}$ & $\begin{array}{l}\text { Relevant microbial tests were } \\
\text { performed during the study } \\
\text { to determine the relevance of } \\
\text { the prescribed antibiotics } \\
\text { Study included multi-centre } \\
\text { Follow-up of patients was } \\
\text { performed after hospital } \\
\text { discharge }\end{array}$ & $\begin{array}{l}\text { Non-randomisation } \\
\text { Purposive sampling }\end{array}$ \\
\hline Oyemolade et al. [28] & Retrospective & $\begin{array}{l}\text { Unnecessary antimicrobial } \\
\text { therapy was reported } \\
\text { Broad spectrum antimicrobials } \\
\text { were mostly used }\end{array}$ & $\begin{array}{l}\text { Clearly stated study objectives } \\
\text { Good sample size effect }\end{array}$ & $\begin{array}{l}\text { Study was conducted in a } \\
\text { single-centre, limiting generali- } \\
\text { sation of findings } \\
\text { Study did not also include } \\
\text { outcome measures }\end{array}$ \\
\hline Illiyasu et al. [29] & Retrospective & $\begin{array}{l}\text { Unnecessary antibiotic therapy } \\
\text { was reported } \\
\text { Frequent use of broad spec- } \\
\text { trum antibiotics was also seen }\end{array}$ & $\begin{array}{l}\text { Clear study objectives, clearly } \\
\text { specified study population }\end{array}$ & Single centre \\
\hline
\end{tabular}


Table 1 (continued)

\begin{tabular}{|c|c|c|c|c|}
\hline References & Study design & Major findings & Strengths & Limitations \\
\hline Ekuma et al. [16] & Retrospective & $\begin{array}{l}\text { High prevalence of antimicro- } \\
\text { bialprescriptions } \\
\text { Non-use of biomarkers to } \\
\text { guide antimicrobial prescrip- } \\
\text { tions }\end{array}$ & $\begin{array}{l}\text { Clearly specified study popula- } \\
\text { tion } \\
\text { Sample size was specified }\end{array}$ & Single centre \\
\hline
\end{tabular}

Table 2 Characteristics of studies on status AMS

\begin{tabular}{|c|c|c|c|c|}
\hline References & Study design & Major findings & Strengths & Limitations \\
\hline $\begin{array}{l}\text { Abubakar and } \\
\text { Tangisuran [30] }\end{array}$ & Cross-sectional & $\begin{array}{l}\text { Very few hospitals had formal AMS } \\
\text { teams }\end{array}$ & $\begin{array}{l}\text { High response rate } \\
\text { Clearly stated research objectives }\end{array}$ & $\begin{array}{l}\text { Excluded primary and secondary tier } \\
\text { hospitals }\end{array}$ \\
\hline Fadare et al. [20] & Cross-sectional & $\begin{array}{l}\text { Low leadership commitment to AMS } \\
\text { in hospitals } \\
\text { Low practice of AMS in hospitals } \\
\text { Few existing formal AMS in hospitals }\end{array}$ & $\begin{array}{l}\text { High response rate } \\
\text { Uniform inclusion and exclusion } \\
\text { criteria } \\
\text { Uniform population of recruited } \\
\text { persons }\end{array}$ & $\begin{array}{l}\text { Excluded one region of the country } \\
\text { Studied AMS in only tertiary hospitals }\end{array}$ \\
\hline Iregbu et al. [31] & Cross-sectional & $\begin{array}{l}\text { Low leadership commitment to AMS } \\
\text { Low existence and poor state of AMS } \\
\text { practice in hospitals }\end{array}$ & Good sample size effect & Study included only tertiary hospitals \\
\hline
\end{tabular}

availability of drugs and information from pharmaceutical representatives. Although this was a single centre study with limited potential for generalisation, it suggests the urgent need for a formal AMS and evidence-based guidelines as relates to antimicrobial therapies. Meanwhile, case definitions resulted from self-reports, which poses a risk of bias.

In a multi-centre study, Abubakar et al. [14] observed high redundant prescription of anaerobic antimicrobial combinations. Daily defined redundant dose was mostly seen in prescriptions for metronidazole. The study noted high and inappropriate use of antimicrobial prophylaxis in women who had obstetrics and gaenocolgy surgeries. Broad spectrum antimicrobial were mostly prescribed and these included nitroimidazoles, in combination with a third generation cephalosporin or beta-lactam/betalactamase inhibitor. This was a nationwide multi-centre, study and therefore, provides better perspective on antimicrobial prescribing in the country. Findings from the study underscore the need for improved antimicrobial stewardship and other institutional interventions including institution-specific antimicrobial guidelines. Meanwhile, only tertiary hospitals were included, which limits generalisation of findings to secondary and primary health centres.

From a retrospective study of 450 paediatrics in a teaching hospital, Roberts et al. found use of antibiotics in some patients who neither had suspected nor confirmed microbial infections [10]. This may have resulted from poor practice of laboratory microbial investigation prior antimicrobial prescription as observed in the study.
Authors had clearly defined primary and secondary outcome measures and clearly stated study objectives, however the single-centre design of the study limits its generalisation.

Similarly, Efunshile et al. found that antibiotics were used without relevant medical indication in the management of acute diarrhoea in children $(<5$ years old $)$ in health facilities [9]. The researchers reported high prevalence of antibiotic prescriptions which was mostly a quinolone (ciprofloxacin). Relevant microbial tests performed during the study to determine the relevance of prescribed antibiotics showed viral infections, indicating unnecessary antibiotic prescriptions. Meanwhile, antibiotic use in acute diarrhoea is discouraged in children by the World Health Organisation [27]. The study was non-randomised and this poses potential limitation to generalisation of findings. Potential lack of awareness and AMS committees may have favoured the observed inappropriate antibiotic prescriptions.

In a 7-month retrospective study from a tertiary hospital database, Oyemolade et al. reported unnecessary antibiotics therapy of neurotrauma patients, prior to neurosurgery [28]. The researchers noted use of antibiotics in a majority of the patients, rather than only in the few who had indications, and abroad spectrum antibiotics was mostly used. The single-centre study included all admitted neurotrauma patients within the study period and reflected apparent need for enlightenment on antimicrobial stewardship. Limitations of this study were noted to include, in-complete information on specific pre-neurosurgical treatment of a significant proportion of cases, in 
its data sources. Also, findings may not be representation of the actual situation, following the single-centre component of the study. The study did not also include clearly stated outcome measures.

In their study, Illiyasu et al. [29] found inappropriate prescriptions of antibiotics among in-patients in an internal medicine ward. Review of patients' case records showed that almost half of the patients were prescribed antibiotics, and this was mostly for community acquired pneumonia. However, this prescriptions were commonly made empirically. This is most likely associated with prescribers' self-confidence in clinical judgment. Meanwhile, cases of de-escalation of the prescribed broad spectrum medications was observed in only very few of the patients. Empirical prescription of third generation cephalosporin as observed by the researchers highlights the need for strict antibiotic guidelines, to discourage emergence of antimicrobial resistance.

Similarly, high prevalence of antimicrobial prescriptions was observed by Ekuma et al. [16] in their study of antimicrobial consumption in a teaching hospital. They also noted poor documentation of reasons for antimicrobial use, and the absence of records on the use of biomakers for guiding antimicrobial treatment. Cephalosporins and metronidazole were most commonly prescribed antimicrobials in the retrospective study.

\section{Status of antimicrobial stewardship programmes in Nigerian hospitals}

There was low presence of formal antimicrobial stewardship (AMS) programme in Nigerian hospitals, as noted in a nationwide cross-sectional-survey by Abubakar and Tangisuran [30]. The researchers found that formal AMS existed in very few hospitals. In the over 6-week survey, it was observed that some AMS strategies were implemented informally, and about half of the participating hospitals evaluated appropriateness of antimicrobial prescriptions, and monitored antimicrobial consumption. Among the barriers noted to impair the establishment of formal AMS teams were lack of support from hospital administrators, lack of training on AMS and inadequate personnel. The survey was conducted through heads of pharmacy departments or pharmacists in charge of infectious diseases. It found that pharmacists actively practiced AMS regardless of lack of formal AMS teams in most hospitals. See Table 2. Although this study provides an insight to the state of AMS programme in Nigerian hospitals, its focus was on tertiary hospitals, which excludes first-hand knowledge about AMS in secondary level hospitals. The study had high response rate and clearly defined objectives, but posing a risk of potential selection bias.
A questionnaire-based cross-sectional study by Fadare et al. [20] also reported that only few tertiary hospitals had a formal Antimicrobial Stewardship Programmes (ASP). Meanwhile, Antimicrobial Resistance (AMR) pattern was seen to influence treatment recommendations in only few of the survey hospitals, and few had formal process for the review of appropriateness of the antimicrobials within $48 \mathrm{~h}$ of use. The study reported low practice of AMS in terms of availability of facility-specific treatment recommendations, formal procedures for reviewing the appropriateness of prescribed antibiotics, monitoring of antimicrobial susceptibility, among others. This study had several strengths including uniform inclusion and exclusion criteria for all respondents, high response rate and uniform population of recruited persons. However, the exclusion of one region of the country in the national survey and exclusion of primary and secondary healthcare facilities poses potential risk of selection bias.

In a national survey of 20 public and private hospitals spread across Nigeria's six geopolitical regions, Iregbu et al. [31] found that very few AMS committees existed across the hospitals. The study also found sparing AMSrelated interventional activities among the hospitals, and there was low leadership commitment to AMS. This poor commitment may have been responsible for the observed non-regular AMS training, monitoring and evaluation of antimicrobial use, including reporting of other antimicrobial activities in the surveyed hospitals. This study highlights the existing gap in availability of AMS teams in Nigerian hospitals and draws attention to the need for AMS awareness among hospital administrators. Some of the identified draw backs in AMS implementations were noted to be lack of AMS knowledge and inadequate communication. The study was characterised by good sample size effect and clearly defined objectives, but like the previous, the study included only tertiary hospitals. The exclusion of other levels of healthcare facilities in the selection potentially poses risk of selection bias.

\section{Discussion}

Available evidence reflect antibiotic overuse and high prevalence of antimicrobial prescriptions particularly broad spectrum antimicrobials for hospitalised patients in Nigeria [9, 15-17, 23, 24, 28]. Epidemiological studies suggest that AMR stems from inappropriate use, such as overuse and underuse of microbial agents [32]. This implies a correlation between antimicrobial consumption and emergence of resistant strains of microorganisms [33]. Countries with high rates of antimicrobial consumption have been shown to have higher rates of microbial resistance [33] potentially leading to several negative health outcomes [34]. Over-prescription of antimicrobials occurs when antibiotics are prescribed 
without indications, which appears to be a regular practice as observed in this review. It is associated with an increased risk of adverse effects and increased health costs [33, 34].

Unnecessary drugs, inappropriate doses and duration of antimicrobials $[9,12,14,17,23,24,26,28,29]$, and poor documentation of prescribed antibiotics $[16,23,28]$ were observed in high proportion among the reviewed studies. Inappropriate antimicrobial prescribing was also a common practice in Cambodia [35]. A previous review of antimicrobial prescribing practices in low and middle income countries also reported high proportion of inappropriate use [36]. Suboptimal antimicrobial prescriptions result in sub-inhibitory concentration, which predisposes the organisms to genetic alterations and resistance to previously used antimicrobials [32]. Hence, suboptimal, inappropriate and unnecessary antimicrobial prescriptions are drivers and contributors of the growing public health threat of AMR [24, 33], especially in low and middle income countries with weak regulations. Therefore, trainings and re-trainings on AMS should be an integral component of practice among prescribers.

Microbiological investigations were seldom performed prior prescription of antimicrobials as prescriptions were mostly empirical $[10,11,15,23,24,29]$. This was also a habitual practice in Cambodia [35]. Laboratory investigations provide basis for definitive diagnosis and promotes the use of a more specific antimicrobial agent as indicated. However, communicable diseases are endemic in Nigeria with high rates of community and hospital acquired infections $[13,19]$. This may be the driving factor for the observed high prevalence of empirical prescribing. Nonetheless, the role of definitive diagnosis should not be completely neglected in antimicrobial prescriptions following its potential in emergence of resistant strains of microorganisms. Multi-drug resistance is a challenge to infection control, and potentially poses life threats in advanced medical procedures such as organ transplantation and dialysis, which require use of effective antimicrobials [37].

Limited or non-observance of existing guidelines for antimicrobial prescribing was also prevalent among the studies $[15,17,23,24,26]$. In a previous study, active dissemination of antibiotic guidelines resulted in a decline in in-patient antibiotic use [38]. This emphasises the relevance of raising awareness and improving information dissemination strategies on relevant guidelines regarding antimicrobial prescribing. Stake holders are urged to ensure regular dissemination and active reminder of existing guidelines to prescribers in Nigeria using easyto-reach media, including workshops, intranet services, facility-based AMS programmes and other forms of trainings. It is also noteworthy that broad spectrum antibiotics were mostly prescribed $[9,14-16,23,24,26,28$, 29 ] as also observed in Cambodia [35]. This is commonly done in empirical prescribing to cater for a wide range of microorganisms. However, this could result in over-prescription or under-prescription which promotes emergence and spread of several resistant species and strains of microorganisms [39]. The access of antimicrobials over-the-counter has also been a major source of AMR promotion in the country [40].

These inappropriate antimicrobial prescribing practices are potential precursors and enhancers of the trending global AMR [32]. These findings reinforce the critical need for AMS in Nigerian Hospitals. However, in spite of this dire need for AMS, formal AMS committees were found to be available in very few hospitals in the country $[20,30,31]$, prompting the urgent need for policies and strategies to redress the noted implementation impediments. Some highlighted barriers to implementation of AMS and formation of ASP include lack of support from hospital administrators, lack of training on AMS, inadequate personnel [30] and poor leadership commitment to ASP [31].

The majority of studies were focused on only tertiary hospitals, thereby excluding evaluation of antimicrobial prescribing practices in primary and secondary healthcare facilities. Meanwhile, the primary and secondary health centres are positioned as first point of call to patients and referral centres respectively. Also, pointprevalence study design was mostly used in the studies. This method does not provide sufficient information on the actual trend, as seen with prospective studies. Nonrandomised sampling observed in some studies also poses a limitation of generalisation of findings from those studies. Similarly, risk of potential self-reporting bias was observed to be associated with some studies.

Although electronic databases with wide spectrum of journals were searched for relevant studies, the inclusion of only five databases may have excluded potentially relevant studies from the review. Only three studies on antimicrobial stewardship status was reviewed, and this may not provide enough basis for an objective conclusion. Nonetheless, findings from this study have brought to limelight the antimicrobial prescribing pattern in Nigerian hospitals, and has highlighted the status of antimicrobial stewardship in the country. Both retrospective and cross-sectional studies where included in the review and this may have resulted in some level of bias in the conclusions. 


\section{Conclusion}

Findings from the study showed high prevalence of empirical prescribing and wide use of broad spectrum antimicrobials, which were mostly prescribed inappropriately with less cognisance to existing guidelines. There was generally poor practice of antimicrobial prescribing, which raises alarm for potential rapid worsening of the already existing state of global AMR. Hence, there is an urgent need for strict antimicrobial guidelines to support clinical decision-making. Policies that facilitate the use of clinical microbiological results are essential to promoting objective antimicrobial prescribing.

Although, there was paucity of studies on the status of AMS in hospitals, the available few studies showed a high deficit of AMS committees in hospitals. There is therefore, an urgent need for policies that promote implementation of AMS in hospitals to improve infection control.

\section{Abbreviations}

AMR: Antimicrobial resistance; AMS: Antimicrobial stewardship; ASP: Antimicrobial stewardship programme; ICU: Intensive care unit; SAP: Surgical antimicrobial prophylaxis.

\section{Acknowledgements}

Not applicable.

\section{Authors' contributions}

COI and UIHE searched the literature for relevant articles. COI synthesized data from included articles and reviewed the manuscript. UIHE significantly contributed to data synthesis and review of manuscript. Both authors read and approved the final manuscript.

\section{Funding}

The study was funded by the authors.

Availability of data and materials

Not applicable.

\section{Declarations}

Ethics approval and consent to participate

Not applicable.

\section{Consent for publication}

Not applicable.

\section{Competing interest}

Authors declare that they have no competing interest.

\section{Author details}

${ }^{1}$ Department of Clinical Pharmacy and Public Health, Faculty of Pharmacy, University of Calabar, PMB 1115, Calabar, Cross River State, Nigeria. ${ }^{2}$ Department of Clinical Pharmacy and Biopharmacy, Faculty of Pharmacy, Olabisi Onabanjo University, Sagamu, Ogun State, Nigeria.

Received: 12 April 2021 Accepted: 11 October 2021

Published online: 26 October 2021

\section{References}

1. Anthony SJ, Ho C (2016) Evaluation and management of community and hospital-acquired pneumonia for the primary care providers. Int J Infect 3(2):e36409. https://doi.org/10.17795/iji-36409

2. Critically important antimicrobials for human medicine. 5th revision. Geneva World Health Organisation 2018. Accessed from https://www. who.int/en/news-room/fact-sheets/details/antimicrobial-resistance

3. World Health Organisation. Promoting rational use of medicines. Accessed from https://www.who.int/home/activities/promoting-rationaluse-of-medicines

4. Maxwell SJR (2016) Rational prescribing: the principles of drug selection. Clin Med (Lond) 16(5):459-464

5. Dyar OJ, Hutter B, Schouten J, Pulcini C (2017) What is antimicrobial stewardship? Clin Microbiol Infect 23(11):793-798

6. World Health Organisation. Antimicrobial stewardship: a competencybased approach. Accessed from https://openwho.org. 1 Apr 2021

7. Centers for Disease Control and Prevention. Antibiotic resistance threats in the United States, 2019. Atlanta, GA: US Department of Health and Human Services, CDC (2019)

8. Mgahurike AA, Idowu I, Igwilo Cl (2010) Antibiotic utilisation and prescribing practices in a Nigerian university medical centre. Nig J Pharm Res. 8(1):236-241

9. Efunshile AM, Ezeanosike O, Nwangwu CC, Konig B, Jokelainen P, Robertson LJ (2019) Apparent over use of antibiotics in the management of watery diarrhoea in children in Abakiliki Nigeria. BMC Infect Dis 19(1):275. https://doi.org/10.1186/s12879-019-3899-1.m

10. Roberts AA, Fajolu I, Oshun P, Osagwu C, Awofeso O, Temiye E, Oduyebo (2020) Feasibility studgy of prospective audit, intervention and feedback as an antimicrobial stewardship strategy at the Lagos university teaching hospital. Niger Postgrad Med J 27(1):54-58. https://doi.org/10. 4103/npmj 11519

11. Ogunleye OO, Fadare JO, Yinka Ogunleye AF, Paramadhas BDA, Godman $B$ (2019) Determinants of antibiotic prescribing among doctors in a Nigerian urban tertiary hospital. Hosp Pract 47(1):53-58. https://doi.org/ 10.1080/21548331.2018.1475997

12. Olayinka AT, Jimoh O, Ejembi J, Ige OT, Lamido Z, Ibrahim A, Aganabor OB (2020) Antimicrobial prescription pattern in a tertiary hospital. Sahel Med J. 23(2):103108. https://doi.org/10.4103/smj.smj_17_18

13. Abubakar $\cup(2020)$ Point-prevalence survey of hospital acquired infections in three acute care hospitals in northern Nigeria. Antimicrobial Resist Infect Control. 9:63. https://doi.org/10.1186/s13756-020-00722-9

14. Abubakar U, Suleiman SAS, Adesiyun AG (2018) Utilization of surgical antibiotic prophylaxis for obstetrics and gynaecology surgeries in northern Nigeria. Int J Clin Pharm 40(5):1037-1043. https://doi.org/10.1007/ s11096-018-0702-0

15. Umeokokwo CD, Madubueze UC, Onah CK, Okedo-Alex IN, Adeke AS, Versporten A, Goossens H, Igwe-Okomiso D, Okrke K, Azuogu BN, Onoh $\mathrm{O}$ (2019) Point prevalence of antimicrobial prescriptions in a tertiary hospital in South Eastern Nigeria: a call for improved antibiotic stewardship. J Glob Antimicrob Resist 17:291-295. https://doi.org/10.1016/j.jgar.2019.01. 013

16. Ekuma AE, Ijezie E, Akpabio T, Onwuezebo IA (2019) Survey of antimicrobial consumption in a teaching hospital in southern Nigeria. Ann Tropical Pathol 10(1):48-51

17. Abubakar U (2019) Antibiotic use among hospitalised patients in Northern Nigeria: a multicentre point-prevalence survey. BMC Infect Dis 20(1):86. https://doi.org/10.1186/s12879-020-4815-4

18. Aldeyab MA, Harbarth S, Vernaz N, Kearney MP, Scott MG, Elhaji FWD, Aldab MA, McElnay JC (2012) The impact of antibiotic use on the incidence and pattern of extended-spectrum-beta-lactamase-producing bacteria in primary and secondary healthcare settings. Br J Clin Pharmacol 74(1):171-179. https://doi.org/10.1111/j.1365-2125.2011.04161.x

19. Iheanacho CO, Eze UIH (2021) Antimicrobial resistance in Nigeria: Charting the way forward. Eur J Hosp Pharm. https://doi.org/10.1136/ejhph arm-002762(inpress)

20. Fadare JO, Ogunleye O, Illiyasu G, Adeoti A, Schellack N, Engler D, Massele A, Godman B (2019) Status of antimicrobial stewardship programmes in Nigerian tertiary healthcare facilities: findings and implications. J Glob Antimicrob Resist 17:132-136. https://doi.org/10.1016/j.jgar.2018.11.025

21. Federal Ministry of Agriculture Environment and Health. National action plan for antibiotic resistance 2017-2022. Abuja, Nigeria (2017) 
22. Moher D, Liberati A, Tetzlaff J, Altman DG, The PRISMA Group (2009) Preferred reporting items for systematic reviews and meta-analysis: the PRISMA statement. PLoS Med 6(7):e1000097. https://doi.org/10.1371/ journal.pmed1000097.

23. Fowotade A, Fasuyi T, Aigbovo O, Versporten A, Adekanmbi O, Goossens $\mathrm{H}$, Kehinde A, Oduyebo $\mathrm{O}$ (2020) Point-prevalence survey of antimicrobial prescribing in a Nigerian hospital: findings and implications on antimicrobial resistance. West Afr J Med 32(3):216-220

24. Kpokiri EE, Taylor DG, Smith FJ (2020) Development of antimicrobial stewardship programmes in low and middle income countries: a mixed method study in Nigerian hospitals. Antibiotics 9(4):204. https://doi.org/ 10.3390/antibiotics9040204

25. Iregbu KC, Osuagwu CS, Umeokonkwo CD, Fowotade AA, Ola-Bello Ol, Nwajiobi-Princewill PI, Taiwo SS, Olayinka AT, Oduyebo OO (2020) Underutilisation of clinical microbiology laboratory by physicians in Nigeria. Afr J Clin Exp Microbiol 21(1):53-59. https://doi.org/10.4314/ajcem.v21i1.7

26. Oshikoya KA, Ogunyinka IA, Adamaigbo C, Olowo-Okere A (2019) Surgical antimicrobial prophylaxis and its dose appropriateness among paediatric patients in a Nigerian teaching hospital. J Chemother 31(6):329-342. https://doi.org/10.1080/1120009x.2019.1615725

27. World Health Organisation. Clinical management of acute diarrhoea

28. Oyemolade TA, Malomo TA, Adeleye AO (2019) Indiscriminate use of antibiotics in neurotrauma patients referred for expert neurological care in a developing Country. J Neurosci Rural Pract 10(4):653-656. https://doi. org/10.1055/s-0039-3399591

29. Illiyasu G, Dayyab FM, Habib ZG, Takwashe IM, Habib AG (2015) Pattern of antibiotic prescription and resistance profile of common bacterial isolates in the internal medicine wards of a tertiary referral centre in Nigeria. J Glob Antimicrob Resist. 3(2):91-94. https://doi.org/10.1016/j.jgar.2015.02. 005

30. Abubakar U, Tangisuran B (2020) National survey of pharmacists' involvement in antimicrobial stewardship programmes in Nigerian tertiary hospitals. J Glob Antimicrobial Resist. 21:148-153

31. Iregbu KC, Nwajiobi-Princill PI, Medugu N, Umeokonkwo CD, Uwaezuoke NS, Peter YJ, Nwafia IN, Elikwu C, Shettima SA, Suleiman MR et al (2021) Antimicrobial stewardship implementation in Nigerian hospitals: gaps and challenges. Afr J Clin Exp Microbiol 22(1):60-66. https://doi.org/10. 4314/ajcem.v22i7.8
32. Ventola CL (2015) The antibiotic resistance crisis. Pharmacy Therap 40(4):277-283

33. Llor C, Bjerrum L (2014) Antimicrobial resistance: risk associated with antibiotic overuse and initiatives to reduce the problem. Ther Adv Drug Saf 5(6):229-241. https://doi.org/10.1177/2042098614554919

34. World Health Organisation. Antibiotic resistance. 2020. https://www.who. int/home/newsroom/fact-sheets/details/antibiotic-resistance. Accessed 27th Sept 2021

35. Om C, Daily F, Vlieghe E, McLaughlin JC, McLaws M (2016) "If it's a broad spectrum, it can shoot better": inappropriate antibiotic prescribing in Cambodia. Antimicrob Resist Infect Control 5:58. https://doi.org/10.1186/ s13756-016-0159-7

36. Sulis G, Adam P, Nafade V, Gore G, Daniels B, Daftary A, Das J, Gandra S, Madhukar P (2020) Antibiotic prescription practices in primary care in low-and middle-income countries: a systematic review and meta-analysis. PLos Med 17(6):1003139.

37. Freidman ND, Temkin E, Carmeli Y (2015) The negative impact of antibiotic resistance. Clin Microbiol Infect 22(5):416-422. https://doi.org/10. 1016/j.cmi.2015.12.002

38. Chandy SJ, Naik GS, Charles R, Jeyaseelan V, Naumova EN, Thomas K, Lundborg CS (2014) The impact of policy guidelines on hospital antibiotic use over a decade: a segmented time series analysis. PLoS ONE 9(3):e92206.

39. Kayode A, Okunroumu P, Plagbende A, Hassan A, Akintola G (2020) High prevalence of multiple drug resistant enteric bacteria: evidence from a teaching hospital in Southwest Nigeria. J Infect Public Health 13(4):651-656.

40. Byarugaba BK (2004) A view on antimicrobial resistance in developing countries and responsible risk factors. Int J Antimicrob Agents 24(2):105-110. https://doi.org/10.1016/j.ijantimicag.2004.02.15

\section{Publisher's Note}

Springer Nature remains neutral with regard to jurisdictional claims in published maps and institutional affiliations.

\section{Submit your manuscript to a SpringerOpen ${ }^{\odot}$ journal and benefit from:}

- Convenient online submission

- Rigorous peer review

- Open access: articles freely available online

- High visibility within the field

- Retaining the copyright to your article

Submit your next manuscript at $\boldsymbol{\nabla}$ springeropen.com 